\title{
"Vamos falar sobre ele?": discursos que (des)constroem as identidades de gênero na escola
}

\author{
Daniel dos Santos Barbosa \\ Universidade Estadual de Goiás \\ daniel.barbosa@seduc.go.gov.br \\ https://orcid.org/0000-0001-9427-8991 \\ Sostenes Lima \\ Universidade Estadual de Goiás \\ sostenes.lima@ueg.br \\ https://orcid.org/0000-0002-1814-3996 \\ Clodoaldo Ferreira Fernandes da Silva \\ Universidade Estadual de Goiás \\ clodoaldoffernandes.silva@ueg.br \\ https://orcid.org/0000-0002-8156-4304
}

RESUMO: Este estudo analisa a reincidência das subalternizações das identidades de gênero e sexualidades, que são invisibilizadas pelo discurso cis-heteronormativo na escola. Identifica nas políticas educacionais elementos para contrapor aos discursos neoconservadores, como o movimento Escola sem Partido. Problematiza o processo de invisibilização de LGBTQIA+ e reflete sobre a promoção e implementação de propostas educacionais em sexualidade e gênero. $\mathrm{O}$ trabalho adota um caráter bibliográfico, com abordagem qualitativa e se baseia em Butler (1990, 2003), Foucault (1988, 1996, 2014), e Louro $(2000,2007,2018)$. Tais teóricos/as problematizam o discurso cis-heteronormativo como um regime opressor para os sujeitos. O corpus se constitui de imagens capturadas de reportagem da Revista Nova Escola e alguns trechos de comentários sobre a matéria. Os resultados demonstram a importância de se discutir questões sobre sexualidades e gênero no âmbito social, promovendo o direito à existência múltipla, sem exclusão de quem não segue o modelo considerado normal.

PALAVRAS-CHAVE: Discursos. Diversidade sexual. Escola. Identidades de gênero.

\section{"LET'S TALK ABOUT IT?": DISCOURSES THAT (DE)CONSTRUCT GENDER IDENTITIES AT SCHOOL}

ABSTRACT: This study analyzes the recurrence of the subordination of gender identities and sexualities, which are made invisible by the cis-heteronormative discourse in school. It identifies elements in educational policies to counteract neoconservative discourses, such as the Escola sem Partido movement. It discusses the process of invisibility of the LGBTQIA+ and reflects on the promotion and implementation of educational proposals on sexuality and gender. The work adopts a bibliographical character, with a qualitative approach and is based on Butler (1990, 2003), Foucault (1988, 1996, 2014), and Louro (2000, 2007, 2018). Such theorists problematize the cis-heteronormative discourse as an oppressive regime for the subjects. The corpus consists of images captured from the Nova Escola magazine article and some excerpts from comments on the matter. The results demonstrate the importance of discussing issues about sexuality and gender in the social sphere, promoting the right to multiple existence, without excluding those who do not follow the model considered normal.

KEYWORDS: Discourse. Sexual diversity. School. Gender Identities. 


\section{CONSIDERAÇÕES INICIAIS}

As discussões sobre diversidade sexual e identidades de gênero têm sido crescentes nos estudos e teorias educacionais, embora, de maneira marginalizada, conforme aponta Tadeu Tomaz da Silva (2000), porém, de forma legítima. Além do ambiente acadêmico, essas discussões também estão em ascensão nas principais mídias sociais. Entretanto, nos espaços escolares essas pautas ainda encontram resistências de grupos neoconservadores, que tentam interferir na função sociocultural da educação. Um exemplo é o movimento Escola sem Partido.

Nessa perspectiva, este artigo visa promover uma análise crítica das identidades LGBTQIA ${ }^{+}{ }^{1}$, invisibilizadas pelo discurso cis-heteronormativo ${ }^{2}$ no ambiente escolar. Esse discurso, presente de forma estrutural, pode ser percebido em ambientes pedagógicos, recreativos e administrativos. Junqueira (2009) e Louro $(2017,2018)$ mostram que a escola tem formado barreiras ao se manifestar e instituir os modelos a serem adotados, não permitindo que sujeitos que fogem a essas normas se reconheçam. Dessa forma, percebemos que o padrão cis-heteronormativo colabora para invisibilidade das identidades dissidentes, configurando-se como uma das mais nítidas formas de opressão.

A escola deve ser o ambiente ideal para construção de novos modelos para se pensar o mundo em toda a sua diversidade e complexidade (GUILOUSKI, 2011). É preciso abordar os temas gênero e sexualidade a fim de garantir o reconhecimento das mais variadas formas de relacionamento humano, para diminuir a intolerância e para desconstruir a naturalidade da heterossexualidade compulsória ${ }^{3}$, promovendo o respeito à diversidade e à valorização cultural. Nesse sentido, recorreremos às políticas públicas inclusivas para pensar e reconhecer a diversidade sexual e as identidades de gênero.

Diante desse contexto, este estudo busca analisar a reincidência das subalternizações das identidades de gênero e sexualidades que têm sido invisibilizadas pelo discurso da cis-heteronormatividade nos ambientes pedagógicos. Especificamente, busca identificar nas políticas educacionais inclusivas elementos para contrapor aos discursos neoconservadores presentes na comunidade escolar; problematizar o processo de invisibilização das identidades LGBTQIA+, marcado pelo discurso cis-heteronormativo nos espaços educacionais; e, por fim, procura refletir sobre a função da escola, como um ambiente de promoção e implementação de propostas educativas em diversidades sexuais e de gênero.

\footnotetext{
1 Esse acrônimo busca inserir a representatividade de diversas formas de manifestação da sexualidade, divergentes da norma social estabelecida entre sexo biológico, concordante com a identidade de gênero e com a heterossexualidade. Abrange formas de expressões afetivo-sexuais, expressões e performatividades de gênero que rompem com padrões e normas sociais de como expressar feminilidade e masculinidade e pessoas que nascem com características sexuais biofisiológicas de pessoas não binárias, como os/as intersexuais, ou pessoas que não expressam atração sexual como os/as assexuais. No campo sociopolítico, a sigla visa demarcar as demandas dos sujeitos representados nessas denominações para afirmar direitos e reconhecimento no âmbito social e jurídico (INTERDONATO; QUEIROZ, 2017).

2 Jesus (2012) distingue pessoas cisgênero de transgênero a partir da concordância (no caso cis) ou da discordância (no caso trans) existente entre a identidade de gênero autodeclarada e o sexo anatômico designado no nascimento. Já a heteronormatividade é uma ordem baseada na centralidade da família heterossexual reprodutiva, com regras que "normatizam e naturalizam a heterossexualidade como modo 'correto' de estruturar o desejo" (BORBA, 2015, p. 96), assim estabelecendo como as pessoas devem se comportar, desejar etc.

3 A expressão "Heterossexualidade compulsória", criada por Adrienne Rich (1980/2010), compreende a heterossexualidade como uma instituição política, em que a mulher tem sido parte da propriedade emocional e sexual dos homens e sua autonomia e igualdade é vista como uma ameaça à família, religião e Estado.
} 
Este artigo adota, inicialmente, uma proposta bibliográfica cuja direção de análise se pauta no método qualitativo, que considera os procedimentos flexíveis ao contexto social. Nessa proposta, a subjetividade do(a) pesquisador(a) e os fenômenos descritos e interpretados acerca da realidade são relevantes para provocar transformações no mundo (FERNANDES; PEREIRA, 2018). Adotamos uma proposta interpretativista de análise a partir do corpus constituído pela revista Nova Escola, edição de fevereiro de 2015, ano 30, n 279, e alguns comentários capturados nessa publicação. Subsidiamos as análises a partir de algumas proposições teóricas foucaultianas sobre discursos, sexualidades e identidades (FOUCAULT, 1988, 1996, 2014; JUNQUEIRA, 2009; SILVA, 2000). Nas discussões sobre a prática cis-heteronormativa no âmbito escolar e estudos queer ${ }^{4}$, recorremos a Borba (2015), Butler (1990, 2003) e Louro (2000, 2007, 2018a, 2018b).

\section{AS IDENTIDADES INVISIBILIZADAS E O AMBIENTE ESCOLAR: DISCURSOS CIS-HETERONORMATIVOS QUE SE CONFIGURAM NA CONTEMPORANEIDADE}

Stuart Hall, considerado um dos precursores nos Estudos Culturais, defende, em suas teorias sobre a construção da identidade, a ideia de descentramento, deslocamento ou fragmentação das identidades modernas $(2001,2014)$. O autor explora a discussão sobre a identidade e diferença, suas implicações e questiona sua provável abrangência (GARCIA; GABLER, 2013). Embora essa discussão seja relativamente recente, Hall (2001) já orientava que as tendências relacionadas a esse tema são ambíguas, e que "o próprio conceito com o qual estamos lidando, 'identidade', é demasiadamente complexo, muito pouco desenvolvido e muito pouco compreendido na ciência social contemporânea para ser definitivamente posto à prova" (HALL, 2001, p. 8).

Dentro dessa perspectiva, também percebemos em Silva (2000) a importância do processo de produção discursiva e social da diferença. $\mathrm{O}$ autor argumenta que a questão da diferença e da identidade não pode ser reduzida a uma questão de respeito e tolerância para com a diversidade. A diferença e a identidade não estão de modo simples tomadas como naturais. Elas são construções culturais e sociais e devem ser questionadas e problematizadas.

Para Silva (2000), identidade e diferença são resultados de atos de criação social e discursiva. Dessa maneira, "significa dizer que não são 'elementos' da natureza, que não são essenciais, que não são coisas que estejam simplesmente aí, à espera de serem reveladas ou descobertas, respeitadas ou toleradas" (SILVA, 2000, p. 73). A afirmação da identidade e a marcação da diferença sugerem os atos de incluir e de excluir. Segundo o autor, a identidade e a diferença se manifestam em declarações sobre quem está incluído e quem está excluído. Portanto, "afirmar a identidade significa demarcar fronteiras, significa fazer distinções entre o que fica dentro e o que fica fora" (SILVA, 2000, p. 67).

Para Louro (2000), uma identidade é definida em relação a outra. Algumas identidades ocupam, culturalmente, uma posição central e servem de referência a todas as

4 Para Louro (2018a), o termo "queer" significa diferente, estranho, esquisito, mas é comumente usado com o significado que no Brasil é nominado "bicha". Em outro sentido, "estudos queer" vão além dessa tradução, impondo-se contra as identidades fixas. Assim, de uma forma ambígua, o termo se coloca como um posicionamento político de resistência transgressiva pela ressignificação do desejo. 
demais. Para a autora, "essas identidades são representadas como 'normais', básicas, hegemônicas. É por contraponto ou comparação a elas que as outras são qualificadas como diferentes" (LOURO, 2000, p. 67). Ainda segundo a professora, estudiosas e estudiosos feministas têm empregado o conceito de gênero para se referir ao caráter fundamentalmente social das distinções baseadas no sexo. Assim, as identidades de gênero nos remetem às várias formas de viver a masculinidade ou a feminilidade (LOURO, 2000).

No Brasil, a identidade tomada referência é representada pelo homem branco, heterossexual, de classe média urbana e cristão (LOURO, 2018b). As identidades que não se enquadram nessa referência são consideradas, precisamente, como "outras". Nessa lógica da diferença e, consequentemente, da subalternização, Oliveira e Ferrari (2020) ponderam que os sujeitos exercem o poder de inserir os corpos desviantes da norma para um lugar inferior, de tal modo que esses corpos são considerados como "os outros", "subordinados", "não legítimos". Contudo, esses mesmos corpos marginalizados, agora, buscam resistências, pois

não é possível afirmar uma identidade natural, mas subjetividades que são construídas a partir de práticas reiterativas, de tecnologias que buscam produzir corpos homogêneos. Entre proibições e afirmações, certo e errado, incentivos e desestímulos, reforço e silêncio, os sujeitos vão se constituindo, mas, nesses processos de poder, estão presentes as resistências, pois nem sempre os corpos serão obedientes e atenderão prontamente à imposição da norma. Antes, darão seus contornos e mostrarão as possibilidades de escape (OLIVEIRA; FERRARI, 2020, p. 48)

Louro (2007) também defende que os sujeitos são constituídos por identidades plurais, múltiplas; identidades que se transformam, que não são fixas ou permanentes, podendo ser até contraditórias. Consequentemente, as lutas identitárias são importantes para o reconhecimento dos corpos que estão à margem e também para autonomia e conquista dos seus direitos.

Diversas áreas do conhecimento têm tentado explicar o fenômeno das identidades. Para Dieguez (2016, p. 523), "a maioria dos estudos abordados preserva a ideia de uma normalização binária, de que o sexo biológico é determinante para a identidade de gênero". A autora também afirma que, segundo essa perspectiva, "existem somente dois gêneros pré-definidos, que são responsáveis por inúmeras características que devem ser seguidas pelos indivíduos". Dessa forma, os sujeitos só se tornam inteligíveis na sociedade a partir de sua identificação com um gênero:

[...] os (sic) transexuais, fugindo a essa lógica do binarismo de gênero, se veem pertencentes a um não lugar social, o que faz com que tarefas simples do dia a dia, como frequentar um banheiro público, se tornem uma dificuldade. Esses sujeitos não se encaixam na lógica dos gêneros, o que faz com que, muitas vezes, busquem realizar intervenções, adequando seus corpos e comportamentos de acordo com o gênero com o qual mais se identificam (DIEGUEZ, 2016, p. 525). 
Para Butler (2003), o sujeito não pertence a um gênero, pois este é construído através da repetição contínua e imitativa de atos performáticos ${ }^{5}$. Portanto, esses atos são inseridos em uma prática reguladora político-cultural que, conforme relata a autora, visa a "[...] uniformizar a identidade de gênero, por via da heterossexualidade compulsória" (BUTLER, 2003, p. 67), ou seja, apenas por uma sexualidade "natural", como considerada pelos movimentos conservadores.

Como efeito da normatização, as identidades dissidentes à cis-heteronormatividade são silenciadas em Projetos Políticos Pedagógicos (PPP), nos livros e materiais didáticos. $\mathrm{O}$ despreparo de alguns docentes e gestores escolares frente à homo/transfobia e outros eventos discriminatórios que ocorrem no cotidiano escolar também são um elemento crucial para a invisibilização das identidades dissidentes. Essa invisibilidade tende a se fortalecer com as discussões sobre a tal "ideologia de gênero" propagada por grupos neoconservadores. Cunha (2016, p. 53) define "ideologia de gênero" como um "pânico moral disseminado que contribui para a invisibilização de sujeitos não-heterossexuais, sobretudo no contexto escolar, impedindo a consolidação dos direitos sexuais no país".

Para Gomes (2012), os processos identitários se constroem gradativamente, iniciando nas primeiras relações sociais, como a família, e percorrendo as outras práticas sociais. A autora ressalta a importância de papéis identificatórios positivos, durante o desenvolvimento e, principalmente, durante a fase escolar. Assim, a representatividade entra como fator importante na construção da subjetividade e identidade dos sujeitos. Nesse sentido, a atuação docente é extremamente importante no enfrentamento ao discurso cis-heteronormativo, não apenas para a formação dos estudantes, considerando as diversidades, mas também para toda a comunidade escolar, principalmente, diante das manifestações neoconservadoras.

Candau (2012) chama a atenção para o fato de que a escola ainda se configura como uma das instituições que tem desempenhado um intenso controle cis-heteronormativo por meio de discursos, silenciamentos e práticas sociais. Essa forma de controle, para Junqueira (2009), interfere na atuação pedagógica de professoras e professores, no desempenho acadêmico dos estudantes e na comunidade em geral. A discriminação por orientação sexual e por identidade de gênero compromete a inclusão educacional e a qualidade do ensino. Segundo o autor, essa repressão "incide na relação docente/ estudante, produz desinteresse pela escola, dificulta a aprendizagem e conduz à evasão" (JUNQUEIRA, 2009, p. 25). Além disso, o autor mostra que a maioria dos/as profissionais da educação não sabe lidar com diversidade sexual. De acordo com esse ponto de vista, é imprescindível repensar a lógica e revelar os mecanismos de exclusão presentes no cotidiano escolar quanto à desconstrução e reconstrução da cultura escolar, como defende Candau (2012, p. 147).

O discurso cis-heteronormativo tem suas raízes nas reproduções de normas, baseadas em argumentos religiosos, políticos e biológicos. Foucault (1988) nos mostra que o

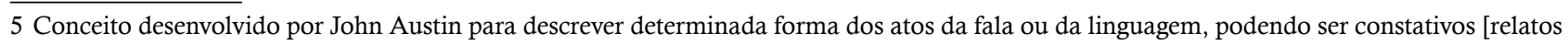
ou descrições] e performativos, que implicam a realização de uma ação (AUSTIN, 1990). 
discurso dominante no século XIX considerava a sexualidade como uma prática reprimida, cuja finalidade se restringia apenas à reprodução. A repressão era uma forma de despertar mais a vontade de saber sobre o sexo, justamente porque carrega essa possibilidade de falar do sexo como libertação ou como um espaço de uma nova lei. Segundo o filósofo, no início do século XIX, ocorreu um deslocamento do olhar sobre a sexualidade conjugal e reprodutiva para as sexualidades periféricas a ela. Nesse período, apenas a sexualidade reprodutiva era considerada pela medicina como uma prática saudável, enquanto as outras manifestações seriam patologias e até crimes. Um exemplo, foi o caso dos/as hermafroditas, que durante muito tempo foram, conforme relata Foucault (1988, p. 39) "considerados criminosos, ou filhos do crime, já que sua disposição anatômica, seu próprio ser, embaraçava a lei que distinguia os sexos e prescrevia sua conjunção".

Buscamos nos postulados da Análise Crítica de Discurso, proposta por Fairclough (2001), contribuições teóricas para ampliar as possibilidades de análise dos discursos cis-heteronormativo. $\mathrm{O}$ autor utiliza o termo discurso para designar "o uso de linguagem como forma de prática social” (p. 90). Para ele, a linguagem, além de ser interação, é também um modo de ação que constrói efeitos de sentidos no ambiente em que os sujeitos circulam. O discurso, gerador de poder, estrutura as concepções, conceitos e práticas das principais instituições sociais, incluindo, certamente, o espaço escolar.

As manifestações das identidades de gênero e das sexualidades dissidentes não estão alheias às relações de interação entre sujeito e sociedade, uma vez que essas manifestações são silenciadas a partir de quem profere a suposta verdade (FERNANDES, 2014). Ao longo da sua história, a escola se estruturou a partir de um conjunto dinâmico de valores, reproduzindo normas e crenças responsáveis por reduzir à figura do "outro" todos aqueles e aquelas que não se sintonizassem com o único componente valorizado pela cis-heteronormatividade. De tal modo, há uma padronização, marcada pelo sujeito "masculino, branco, heterossexual, burguês, física e mentalmente "normal"" (JUNQUEIRA, 2009, p. 14). Louro (2018a) afirma que "aqueles sujeitos que fogem da norma e promovem uma descontinuidade na sequência sexo/gênero/sexualidade são alocados em grupos de minorias e colocados à margem" (p. 27). Dessa maneira, esses grupos minoritários acabam sendo necessários, uma vez que dão proeminência aos grupos considerados "normais".

De acordo com Borrillo (2016, p. 3), "a homofobia é uma manifestação arbitrária que consiste em designar o outro como contrário, inferior ou anormal". É um constructo decorrente dos discursos que são produzidos e reproduzidos pelas instâncias socializadoras e que reafirmam a lógica dicotômica sexista e da [cis-] heteronormatividade compulsória (FOUCAULT, 1988 apud LOURO, 2018a).

Borba (2015), nos seus estudos, considerados como segunda fase da Linguística Queer, analisa criticamente a cis-heteronormatividade por meio de uma visão linguística que é permeada por conceitos das teorias queer. Observa, particularmente, como esse discurso cis-heteronormativo é sustentado ou subversivo. Nesse contexto, compreendemos 
que a Linguística Queer viabiliza alternativas a discursos cis-heteronormativos e fomenta seu uso para contribuir para mudanças sociais concretas e identificar os discursos hegemônicos presentes nas práticas sociais.

Do mesmo modo, Butler (2003) divulga sua teoria sobre gênero a partir da noção de atos performativos, que constituem de forma social, política e culturalmente o gênero do indivíduo. Nesse sentido, a autora ressalta que muitos atos de fala, tais como "É uma menina" "Meninos não choram", não apenas "descrevem o corpo de uma criança, mas reproduzem, performativamente, ideias sobre gêneros e sexualidades que, através da repetição ao longo do tempo, ganham a aparência de serem naturais e normais" (BUTLER, 2003, p. 67, apud LEWIS, 2018, p. 677).

A cis-heteronormatividade é marcada, no ambiente escolar, por mecanismos de controle que buscam alcançar o corpo do sujeito, e também reforçar a norma a ser seguida por docentes e discentes. O poder disciplinar é exercido nessa experiência. Ele controla continuamente todos, até os que estão encarregados de controlar (FOUCAULT, 2014, p. 174). Nessa perspectiva, podemos problematizar a tese de Oliveira e Ferrari (2020, p. 51), sobre "como a heteronormatividade é um regime opressor para todos os sujeitos, até para aqueles e aquelas que se afirmam como heterossexuais", pois precisam "se mostrar adequados ao masculino". Essas situações devem ser abordadas na escola, tendo em vista a criação de condições de equidade de acesso e aprendizagem. Junqueira (2009, p. 58) explica que, no caso dos estudantes LGBTQIA+, "é preciso superar a visão normatizadora e homogeneizadora, que preconiza que os diferentes devem se adaptar às regras e conceitos de 'normalidade'". Para o autor, esse trabalho voltado a problematizar e a subverter as práticas discriminatórias, requer, entre outras coisas,

[...] pedagogias, posturas e arranjos institucionais eficazes para abalarem estruturas e mecanismos de [re]produção das desigualdades e das relações de forças. E mais: que também permitam a busca por alternativas às estratégias de invenção e fomento de vínculos identitários pautados por vitimismos, ressentimentos e ódios. Estes últimos, oriundos de autorrepresentações narcísicas, desatentas à modulação da própria alteridade - e de suas relações de poder - e avessas à necessária ampliação das possibilidades de identificação e de alianças - quer com os "diferentes" invisibilizados dentro do grupo, quer com os de fora (JUNQUEIRA, 2009, p. 58).

Nesse sentido, acreditamos que a escola ao criar obstáculos (uma vez que decide manifestar e determinar os modelos a serem seguidos) não permite que o sujeito se reconheça, tornando-se, assim, um ambiente discriminatório. No entanto, a escola deve oferecer elementos para construir a autonomia e criticidade de seus educandos e de todos que ali transitam, começando pela inclusão de seu corpo discente que se identifica com essas diversidades. Também se faz necessário a aplicação das políticas públicas de inclusão direcionadas para as minorias, ou seja, de uma educação para a diversidade e para a valorização da cultura nas suas diferentes interfaces. 


\section{POLÍTICAS PÚBLICAS INCLUSIVAS PARA EDUCAÇÃO}

Nas últimas décadas, houve um avanço nas produções científicas que abordam temas relacionados à diversidade sexual e aos estudos de gênero, tais como os estudos de Louro (2017), Borrillo (2016), Oliveira (2020), Junqueira (2009), entre outros. Esses estudos ganharam importância para a academia e, simultaneamente, contribuíram para a expansão da visibilidade política de movimentos sociais. Netto (2011) considera como conquista histórica a criação do Programa Nacional de Direitos Humanos (PNDH), em 1996 e 2002, e do Programa Brasil sem Homofobia, em 2004. Essas políticas de inclusão foram aprovadas, de acordo com o autor, com a "finalidade de prevenir a violência contra grupos em situação de vulnerabilidade e implantar as discussões sobre orientação sexual como objeto de políticas públicas" (NETTO, 2011, p. 78-79).

Nesse contexto, temos vivenciado um momento particular na educação brasileira. Durante os governos Lula e Dilma (2003-2016), houve um avanço significativo nas políticas educacionais, como um todo, e especialmente no que diz respeito às políticas de reconhecimento das diferenças, de valorização das diversidades e de democratização da escola e da educação pública. No entanto, no governo Bolsonaro (2019-), verificamos que o Ministério da Educação tem assumido, como política oficial de governo, uma perseguição ao que chamam pelos epítetos de "ideologia de gênero", "marxismo cultural", "doutrinação", entre outros termos.

Além disso, outras preocupações vêm surgindo nos últimos anos, como os movimentos neoconservadores. Um exemplo é o movimento Escola sem Partido. Esse movimento inspirou projetos de leis por todo o país, nas esferas municipais, estaduais e federal. A proposta também restringe a educação sexual, uma vez que docentes só poderiam abordar esse tema em sala de aula com a permissão das/os responsáveis pelas/os estudantes. Dessa forma, os estudos de gênero e orientação sexual estariam banidos dos componentes curriculares.

De acordo com a professora Dani Balbi, doutora em Letras pela UFRJ e diretora Nacional da UNALGBTQIA+, não há atualmente políticas públicas de inclusão ou debate sobre diversidades no contexto escolar. Para Balbi, essa exclusão decorre "das diversas omissões que os agentes da educação constroem em relação à transfobia nesses espaços, o que resulta em mais de $70 \%$ de pessoas trans e travestis abandonando o ensino básico" . Ainda, segundo a professora, esse é um dos fatores determinantes para que cerca de $80 \%$ a $90 \%$ das pessoas que se autodeclaram transexuais e travestis estejam no mercado da prostituição, fora do mercado formal (GANDRA, 2019).

Em seus objetivos gerais, os Parâmetros Curriculares Nacionais (BRASIL, 1997) defendem que a escola deve ser responsável por ensinar aos estudantes o respeito à diversidade de valores, crenças, comportamentos referentes à sexualidade, reconhecendo, portanto, as diferentes configurações de sexualidade e o seu direito à expressão. Fontes

6 Trecho citado na reportagem "Escola é primeiro gargalo à inserção de pessoas trans no mercado", de Alana Gandra, publicada em 06 nov. 2019, no site da Agência Brasil. Disponível em: https://agenciabrasil.ebc.com.br/geral/noticia/2019-11/escola-e-primeiro-gargalo-insercao-de-pessoas-trans-no-mercado. Acesso em: 13 jul. 2021. 
(2008, p. 10) ressalta que o esperado é que os materiais didáticos fornecessem aos profissionais da educação a base para que esse direito fosse garantido. A autora mostra, no entanto, que, "no conjunto de obras aprovadas pelo PNLD, o que predomina sobre essas temáticas é o silêncio" (FONTES, 2008, p. 10).

Nessa perspectiva, recorremos às políticas públicas inclusivas para pensar e reconhecer a diversidade sexual e as identidades de gênero. Essas políticas se estruturam em legislações vigentes, tais como: Constituição Federal de 1988, Lei de Diretrizes e Bases da Educação - LDBEN (Lei no 9.394/1996), PCNs (1997), Diretrizes Curriculares Nacionais Para Educação Básica - Diversidade e Inclusão (2013) e Plano Nacional de Educação (2004).

Cabe enfatizar que, no documento Base Nacional Comum Curricular ${ }^{7}$ (BNCC), em sua versão final, os termos gênero e orientação sexual foram suprimidos por pressão de grupos ideológicos e religiosos, tal como ocorreu na atualização do PNE - 2014-2024 (MENDES, 2020). Assim, permaneceram apenas as referências às diversidades de forma genérica. Já o termo "gênero" é empregado somente ao se fazer referência aos gêneros textuais/discursivos. Ettrich (2019, p. 6-7) mostra que a BNCC não apresenta uma parte específica que trata do tema transversal ligado à sexualidade, como consta nos $\mathrm{PCNs}$. Na introdução, a BNCC apresenta apenas "competências gerais, sendo uma delas destinada ao respeito como valor a ser desenvolvido".

As discussões sobre a sexualidade e identidades de gênero podem esbarrar em preconceitos relativos à estereotipação de papéis masculinos e femininos. Em 2011, o material pedagógico produzido por especialistas e encomendado pelo Ministério de Educação, intitulado como Kit Anti-homofobia, foi muito discutido no Brasil. Entretanto, a iniciativa não resistiu às pressões de congressistas, ligados a instituições religiosas, o que levou o governo federal a impedir o andamento do projeto.

Um levantamento realizado pelo Grupo Gay da Bahia ${ }^{8}$ revela que, a cada 33 horas, um homossexual é assassinado no país. Nesse contexto, é necessário refletir sobre como a educação pode contribuir para promover a diversidade, romper com estigmas estruturais e combater a violência. A instituição também mostra que aconteceram 445 mortes, em 2017, e 420, em 2018, de pessoas LGBTQIA+, vítimas da homofobia. Louro (2018a) explica que essa violência resulta da ignorância. Ou seja, a falta de conhecimentos sobre a diversidade sexual se transforma em aversão e ódio.

Em fevereiro de 2015, a revista Nova Escola trouxe à tona a história do britânico Romeo Clarke, de 05 anos, que foi expulso do contraturno escolar por usar vestido e também uma tiara de princesa. A partir desse fato, essa discussão tomou grandes dimensões, não apenas no Reino Unido, mas também em vários países, inclusive no Brasil.

\footnotetext{
7 A Base Nacional Comum Curricular é um documento normativo que define o conjunto de aprendizagens essenciais que todas e todos estudantes devem desenvolver ao longo das etapas e modalidades da Educação Básica. Brasília, DF: MEC, 2015. Disponível em: http://basenacionalcomum.mec.gov.br. Acesso em 09/12/2020.

8 HERMANSON, Marcos. Relatório registra 420 vítimas fatais de discriminação contra LGBTs no Brasil em 2018. Brasil de Fato. São Paulo. Disponível em: https://www.brasildefato.com.br/2019/02/08/relatorio-registra-420-vitimas-fatais-de-discriminacao-contra-lgbts-no-brasilem-2018. Acesso em 12 jan. 2021.
} 


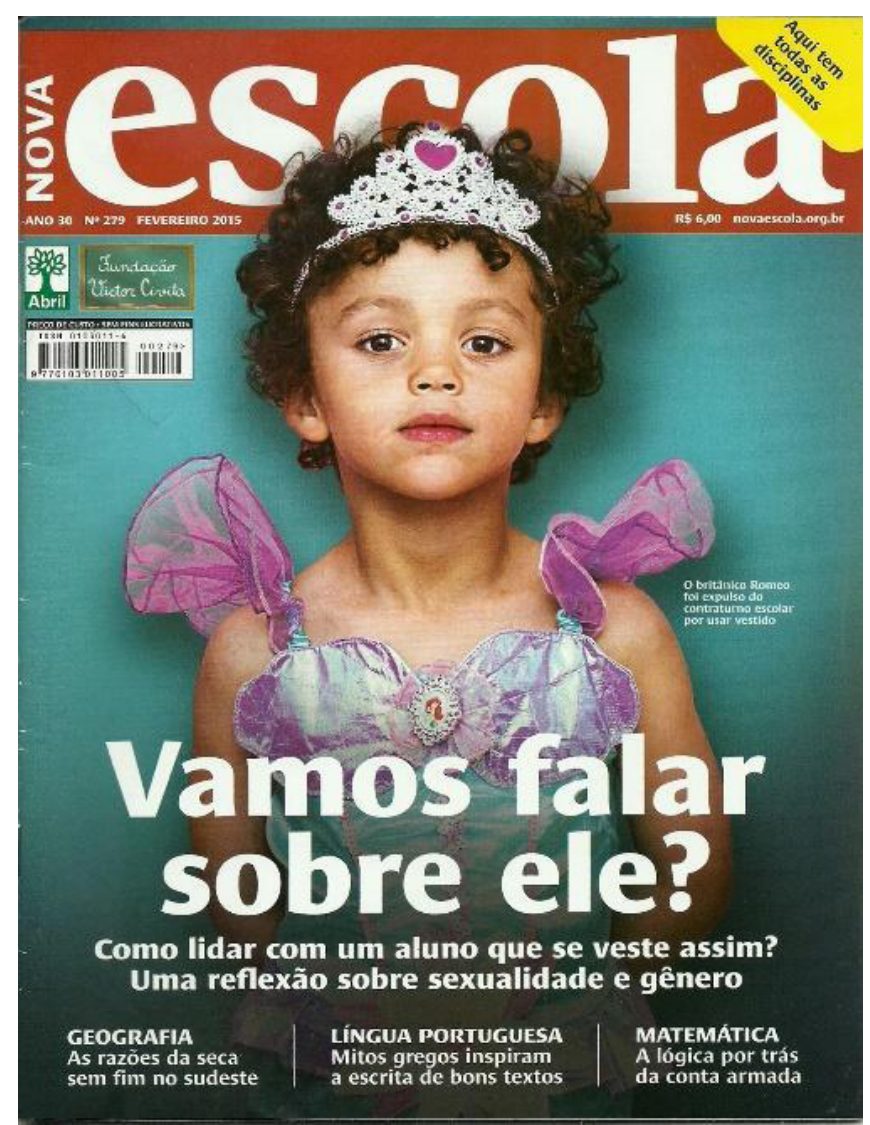

Figura 1: Capa da revista Nova Escola, edição no 279/2015. (Crédito: Newsteam/ SWNS Group/ Grosby Group). Disponível em: https://novaescola.org.br/conteudo/80/educacao-sexual-precisamos-falar-sobre-romeo. Acesso em: 10 jan. 2021.

A matéria principal dessa edição recebeu o título "Educação sexual: precisamos falar sobre Romeo..." e o subtítulo "Iana, Roberta e Emilson. A escola trata com preconceito quem desafia as normas de papéis masculinos e femininos". A matéria apresentou depoimentos de estudantes que passaram por situações que evidenciam o modelo cis-heteronormativo.

A figura 1 nos fornece elementos para uma reflexão sobre a tentativa de amordaçar as identidades num viés estável, coerente e monolítico que oprime a existência e nega direitos a ela. O texto imagético mostra que os corpos são fluidos e os gêneros estão em constante movimento, que funcionam numa heterogeneidade. O ser homem e o ser mulher dicotômicos não cabem numa perspectiva múltipla. Daí a importância de evitar as categorizações normalizantes e biologizantes no espaço escolar.

A figura 1 traz à tona a interpretação da diferença como monstruosidade. Como bem apontado pelo pensador francês Michel Foucault (2010), os sujeitos que fogem da "normalidade" são categorizados como monstros humanos. Segundo ele, a ideia daquilo que não podemos nomear causa desconforto. Afinal, que nome dar a uma figura excêntrica que, além de representar o proibido, ainda incorpora elementos considerados impossíveis? Nesse sentido, podemos dizer que a imagem da capa evidencia um diálogo com o monstro humano foucaultiano na medida em que a criança se mostra como transgressora de duas relevantes instâncias: as leis da sociedade e as leis da natureza (FER- 
NANDES, 2014). O jogo de linguagem proposto pela capa (Vamos falar sobre ele?) e a figura considerada monstruosa e desviante (um suposto menino vestido de uma suposta menina, que desconstrói o binarismo e problematiza o modelo considerado "normal") chamam-nos a atenção, pois é a partir desses questionamentos materializados em discursos (re)atualizados que moldamos ações no mundo, podendo transformá-lo (FAIRCLOUGH, 2001).

Vejamos, em seguida, a figura 2 e o relato, de acordo com a reportagem:

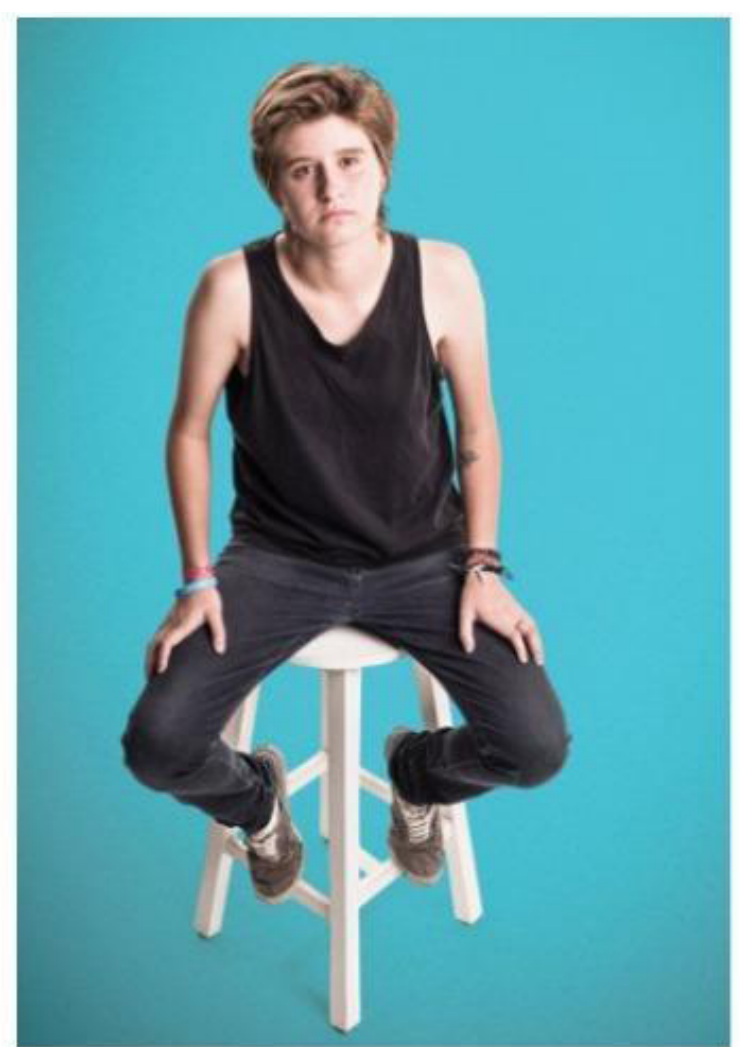

Figura 2: Iana Mallmann, 18 anos, ex-aluna das redes pública e privada de Brasília. (Crédito: Alexandre A. Bastos). Disponível em: https://novaescola.org.br/conteudo/80/educacao-sexual-precisamos-falar-sobre-romeo. Acesso em: 10 jan. 2021.

A estudante Iana Mallmann, 18 anos, relatou a repressão que sofreu em uma escola privada de Brasília por não se identificar com as roupas e acessórios femininos, não se sentar de pernas cruzadas e ainda manifestar seu sentimento afetivo por uma colega de classe. A aluna foi abordada várias vezes por professores e professoras, e pela coordenação da escola, com discursos como: "tudo bem você ser homossexual, mas não fale disso na escola".

Os enunciados produzidos por alguns docentes mostram como os discursos moldam realidades, classificam, invisibilizam e discriminam (outras) identidades (FERNANDES; PEREIRA, 2012). Essas práticas se configuram numa subalternização das existências e corpos. Como bem nos ensina Moita Lopes (2006), discursos assim se constituem numa prática perversa que constrói valores de verdade por meio de significados legitimados. $\mathrm{O}$ "não falar disso na escola" demonstra o quanto esses espaços pretendem que a sexualidade (especialmente aquelas consideradas diferentes) seja deixada do lado de fora dos 
muros, reprimida, silenciada. Entretanto, a sexualidade faz parte da escola e da nossa constituição; não podemos nos despir dela, nem tampouco, desligá-la (LOURO, 2010).

Outro caso abordado na edição foi do estudante Emilson, de uma escola pública tradicional do Rio de Janeiro. O estudante, que se considera agênero ${ }^{9}$, compareceu à escola usando uma saia (do uniforme escolar), que tomou emprestado de uma colega, e foi repreendido pela direção.

Como as organizações estudantis são muito presentes nessa instituição, nas semanas seguintes, os estudantes organizaram um saiato (figura 3), como forma de protesto. Mais de 30 discentes foram de saias à escola no dia marcado. $\mathrm{O}$ caso repercutiu em diversos veículos de comunicação. Casos como esse mostram o quanto a linguagem é mediação necessária para problematizar a vida cotidiana. É por meio dela que agenciamos as nossas demandas e reivindicamos o direito à existência. Podemos dizer que o saiato se apresenta como uma proposta discursiva de questionar o mundo por meio de práticas sociais e relações que desestabilizam e (re)inventam as estruturas sociais (FAIRCLOUGH, 2001).

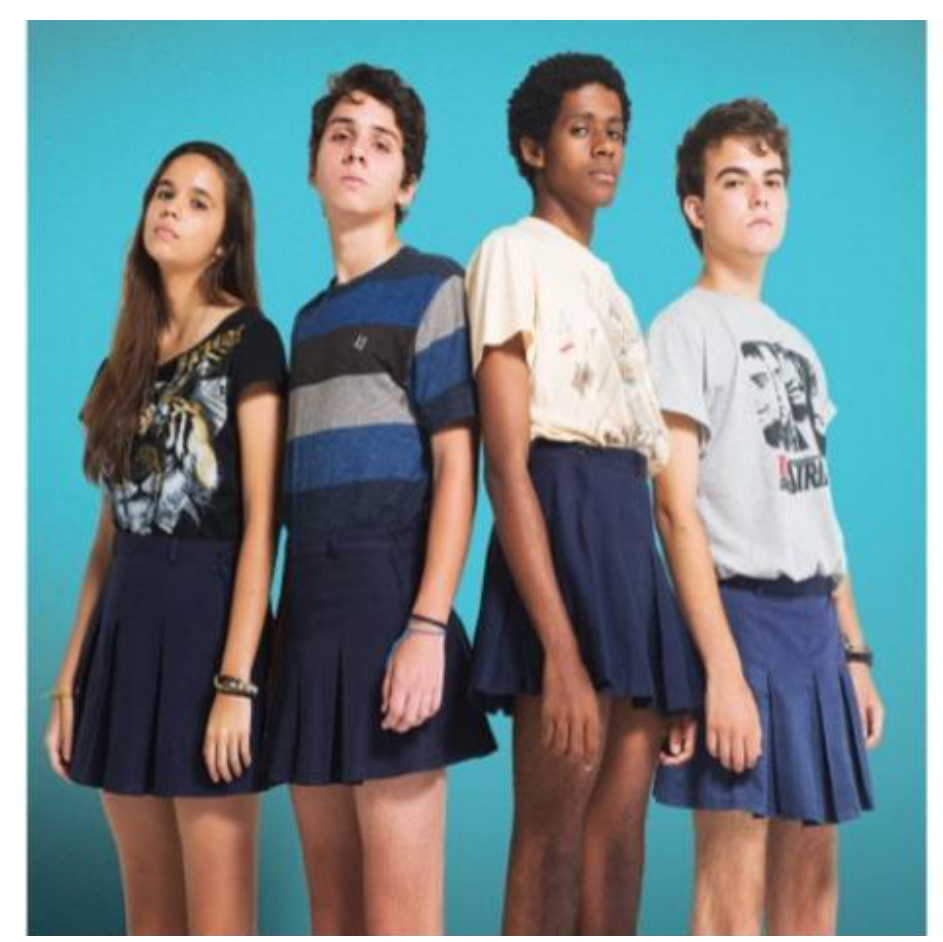

Figura 3: Estudantes protestaram pelo direito de Emilson (blusa bege) usar saia. (Crédito: Lucas Landau). Disponível em: https://novaescola.org.br/conteudo/80/educacao-sexual-precisamos-falar-sobre-romeo. Acesso em: 10 jan. 2021

De acordo com Santos Filho (2015), essa matéria da revista foi suficiente para que alguns dos leitores e leitoras apresentassem questionamentos do tipo: "Em que mundo estamos vivendo?". Os comentários indicam que boa parte da sociedade ainda considera que não é aceitável tal destaque ao assunto, não é aceitável a fotografia na capa, bem como não é aceitável a própria existência do Romeo (SANTOS FILHO, 2015). Embora

9 De acordo com Camila Nishimoto (2020) o termo agênero refere-se a uma identidade em que a pessoa não se identifica com nenhum gênero. @TODXBrasil. 19 maio 2020. Disponível em: https://medium.com/todxs/dia-do-orgulho-agenero-guia-básico-para-entender-essa-identidade-e2edea5e9ab2. Acesso em: 23 fev. 2021. 
seja inevitável a manifestação de comentários dessa natureza, a publicação da matéria exerceu um papel sociodiscursivo importante, pois trouxe para o campo do debate social outros discursos e outras formas de representação do mundo. Mudanças sociais importantes só são possíveis quando outras formas de representar o mundo entram em circulação, passando a disputar espaço com as representações já naturalizadas.

Para encerrar, apresentamos a seguir alguns comentários de leitoras e leitores, publicados no site da revista sobre o tema abordado nessa edição:

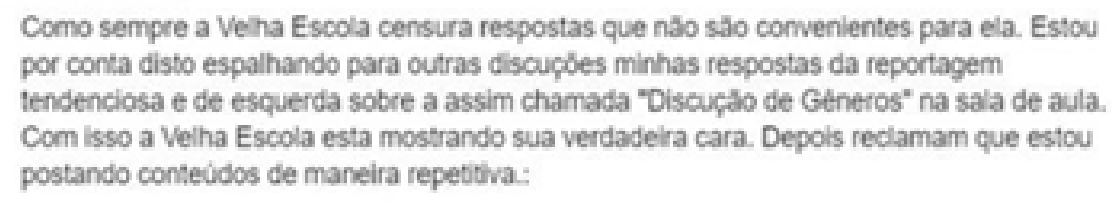

Nä̊ existe gènero na Biologla apenas sexo masculino e feminino. Gènero so em Portuguès. 0 que existe tambem é a Ideologia esquerdopata de Generos que so faz "empoderar" quem é fraco das idelas. Nao precisamos falar disso de modo nenhum. Cada um com suas particularidades nāo sou eu que irei apolar ou condenar a opçăo dos alunos. Näo irei fazer apologia a pretensa liberdade a todo custo.

Paralelo a isso estou encaminhando para os devidos canals, servicos de assinatura desta publicaçà marrom, da fundaça que a financia, bem como associpoles de jornalistas, a agencias reguladoras, reclamaçăo formal e devidos prints de tela.

Curtir Responder 04 - 3 a

Figura 4: Comentário sobre a capa da revista Nova Escola, edição no 279/2015.

Disponível em: https://novaescola.org.br/conteudo/80/educacao-sexual-precisamos-falar-sobre-romeo. Acesso em: 21 jun. 2021.

Figura 5: Comentário sobre a capa da revista Nova Escola, edição n ${ }^{\circ}$ 279/2015.

Disponível em: https://novaescola.org.br/conteudo/80/educacao-sexual-precisamos-falar-sobre-romeo. Acesso em: 21 jun. 2021.

Isso é uma merda mano...

Quer ser homossexual/heterosexual escola n é lugar de impor isso

Curtir - Responder $\cdot 3$ a

Figura 6: Comentário sobre a capa da revista Nova Escola, edição nº 279/2015.

Disponível em: https://novaescola.org.br/conteudo/80/educacao-sexual-precisamos-falar-sobre-romeo. Acesso em: 21 jun. 2021.

Os excertos acima mostram o quanto precisamos problematizar a diversidade. $\mathrm{Na}$ figura 4, por exemplo, há elementos que nos sinalizam a tentativa de calar o corpo, a subjetividade e a experiência do outro. Percebemos a demonização de uma suposta política de esquerda para a "Discussão de Gêneros" na sala de aula. O excerto "não existe gênero na biologia, apenas sexo masculino e feminino" indica o potencial constitutivo dos discursos nas práticas sociais. Dito de outra maneira, esse recorte mostra o modo como as pessoas podem, de forma rotineira, ritualizada e institucionalizada, agir sobre os ou- 
tros, impondo uma dada representação do mundo (FAIRCLOUGH, 2001). Assim, a linguagem é promotora e reprodutora de ideologias que se materializam em sistemas de dominação que privilegiam determinadas representações em detrimento de outras (FERNANDES, 2014). A concepção biologizante da sexualidade acima confirma o quanto a linguagem é atravessada pelo poder, veiculando-o, promovendo sentidos de normalidade, ditando quais modelos devemos seguir, naturalizando os nossos modos de perceber o mundo (LOURO, 2010).

Uma escola que não aceita em seu locus a diversidade, cujo lugar se propõe somente se constituir num espaço que executa conteúdos curriculares (figura 5 e 6), evidencia a importância da promoção de questionamentos e dissidências discursivas. Afinal, uma escola que ignora esses assuntos e nega a condição múltipla da existência humana (diferentes modos de ser e existir) acaba sendo apenas um dispositivo de controle, que promove a cis-heteronormatividade e silencia as sexualidades e identidades de gênero dissidentes (FERNANDES, 2014). Portanto, defendemos que a pedagogização da norma da sexualidade não é e não pode ser uma forma de separar o corpo da mente, descorporificando docentes e estudantes no âmbito da escola (MOITA LOPES, 2008).

Sobre a revista Nova Escola, Santos Filho (2015) afirma que ela teve um salto importante de qualidade na formação docente no que concerne a questões de sexo, sexualidade e gênero, por se preocupar com o desenvolvimento saudável psicossocial. O autor afirma que a revista responde bem ao questionamento "Em que mundo estamos vivendo?", quando publica uma reportagem que discute os conceitos de sexualidade e gênero. Há uma preocupação com a produção de um outro conhecimento sobre os diversos sujeitos que lutam por voz e vez na sociedade, sujeitos esses que estão diariamente em nosso convívio e que ainda são vítimas das mais diversas atrocidades pelo fato de vivenciarem outras formas de ser e existir (SANTOS FILHO, 2015).

Essa é uma discussão, embora nem sempre explícita, muito importante, porque aborda a maneira como a sociedade constrói, às vezes de forma injusta, hierarquias e classificação para papéis humanos com base em estereótipos de sexualidade. Para Louro (2017, p. 28), esses papéis estão relacionados aos "padrões ou regras arbitrárias que uma sociedade estabelece para seus membros e que definem seus comportamentos e seus modos de se relacionar ou de se portar".

Embora as identidades de gênero e a orientação sexual não estejam explicitamente contempladas na BNCC, a nona competência ${ }^{10}$ faz referência à promoção do respeito ao outro e aos direitos humanos, com acolhimento e valorização da diversidade, sem preconceito de qualquer natureza. Nesse sentido, é que essa discussão sobre gênero e sexualidade deve ser uma das funções da escola. Além disso, a sexualidade deve ser um assunto curricular para pensarmos sobre a constituição do jovem. A discussão do tema oferece bases para a criança quando ela começa a se perguntar o que é o masculino e

10 "Empatia e cooperação: Exercitar a empatia, o diálogo, a resolução de conflitos e a cooperação, fazendo-se respeitar e promovendo o respeito ao outro, com acolhimento e valorização da diversidade de indivíduos e de grupos sociais, seus saberes, identidades, culturas e potencialidades, sem preconceitos de origem, etnia, gênero, orientação sexual, idade, habilidade/necessidade, conviç̧ão religiosa ou de qualquer outra natureza, reconhecendo-se como parte de uma coletividade com a qual deve se comprometer" (BRASIL, 2017). 
o que é o feminino, ou mesmo quando começa a se reconhecer como um determinado gênero, como por exemplo, no caso do Romeo, em que ele não se vê dentro dos padrões que são estabelecidos para o masculino (XAVIER FILHA, 2015).

Lopes (2003) observa que um garoto pode ser objeto de escárnio por parte de colegas e professoras e professores antes mesmo de se identificar como gay. Por isso, essa discussão é uma questão social, uma tarefa a ser cumprida pelos docentes, como consta nos PCN: "Espera-se que o aluno aja sem discriminações em relação ao comportamento dos outros, não depreciando atitudes e formas de expressão assumidas por pessoas do sexo oposto" (BRASIL, 1997. p. 151).

A diversidade sexual deve ser discutida como um tema transversal importante. O/A educador/a deve dar condições para que alunas e alunos aprendam a agir sem discriminações em relação ao comportamento alheio. Em relação à homofobia na escola, fazemos coro à denúncia de Louro (2018b, p. 29): "consentida e ensinada na escola, a homofobia expressa-se pelo desprezo, pelo afastamento, pela imposição do ridículo".

\section{CONSIDERAÇÕES FINAIS}

O fato relatado na matéria da Revista Nova Escola, que culminou na repreensão aos estudantes, evidencia o despreparo das instituições escolares, tanto da rede pública quanto da rede privada. É preciso pensar em formação continuada de docentes em matéria de diversidade sexual, para que haja uma discussão qualificada sobre a temática na escola, proporcionando condições de equidade, de acesso e aprendizagem a todas e todos, garantindo, assim, o respeito à diversidade de valores e de comportamentos (XAVIER FILHA, 2015).

É importante enfatizar que a abordagem do tema pode ser uma atribuição apenas de educadoras e educadores, sob o risco de se criar uma forma de perseguição a esses profissionais por parte de grupos conservadores. Essa é uma questão a ser debatida em todas as instituições sociais. Lembremos que, se um garoto andasse pela rua ou praça usando vestido, isso também provocaria algum tipo de reação, com possibilidade até de violência. Existe um pânico moral que atravessa todas as dimensões da vida social. As pessoas, ao se defrontarem com essas fronteiras de gênero, estão, também, cruzando as fronteiras da determinação hegemônica da sexualidade. Por isso é importante que haja um engajamento amplo de vários setores da sociedade (POCAHY, 2015).

Os agentes educacionais (gestores e docentes) devem fazer valer o compromisso que assumem com a formação plena do ser humano. Pensando a educação como uma prática política para a cidadania, as instituições e agentes da educação devem assegurar a liberdade de expressão e entender que expressões ligadas a gênero e sexualidade são fluidas e situadas historicamente, em vez de uma determinação natural, estável e segura (POCAHY, 2015). E certas convenções sociais ligadas à sexualidade podem ser violentas para determinados grupos sociais.

As construções sociais em torno da sexualidade buscam conferir certa inteligibilidade entre os corpos (SANTOS; LUCINI, 2016, p. 155). Desse modo, macho e mascu- 
linidade, fêmea e feminilidade são coisas consequentes (VALE DE ALMEIDA, 1996). É como se nós vivenciássemos essas experimentações como naturais, enquanto, na verdade, se configuram mais como um reflexo de uma norma, sendo a expressão de uma convenção social.

Essas questões são importantes para a formação docente, uma vez que a escola é um espaço político importante do exercício da liberdade das crianças e adolescentes. As universidades, os movimentos sociais e educadoras e educadores têm se engajado nesse movimento político de formar o/a docente para que ele/ela possa pensar/ensinar essas questões de forma inclusiva, livre dos preconceitos e discriminações que ainda vigoram em nossa sociedade.

As políticas sociais e educacionais têm funcionado como proposta possível para garantir os direitos de toda cidadã e todo cidadão. O exercício pleno da cidadania só é possível quando direitos humanos e civis básicos são promovidos pelas instituições sociais formadoras, garantindo ampla liberdade e aceitação para as mais variadas formas de ser e existir no mundo. Dessa forma, concordamos com Silva e Filho (2016, p. 06): "as políticas de acesso, permanência e sucesso de estudantes e suas diversidades ainda necessitam de consolidação, de forma a garantir a todos/as todos os direitos em suas particularidades". Em suma, essas políticas públicas inclusivas reforçam e garantem o direito à cidadania.

Por fim, alertamos que, apesar de já haver muitos estudos relacionados à diversidade, esse campo ainda carece de pesquisas mais aprofundadas. Atualmente, ainda notamos que parte das intervenções escolares em situações discriminatórias é fundamentada na lógica do senso comum, que só repete a norma e os discursos hegemônicos. Destacamos, portanto, a relevância da formação do/a docente no enfrentamento das desigualdades presentes na escola. Uma boa formação contribui para a implementação de uma cultura direcionada à garantia dos direitos humanos.

\section{REFERÊNCIAS}

AUSTIN, John Langhaw. Quando dizer é fazer: palavras e ação. Porto Alegre: Artes Médicas, 1990.

BELMONTE, Pilar et al. História da homossexualidade: ciência e contra-ciência no Rio de Janeiro (1970-2000). Tese de Doutorado, Casa de Oswaldo Cruz/Fiocruz. Rio de Janeiro, 2009.

BORBA, Rodrigo. Linguística Queer. Uma perspectiva pós identitária para os estudos da linguagem. Entrelinhas, Rio de Janeiro, v. 9, n. 1, p. 91-107, 2015. Disponível em: http://revistas.unisinos.br/index.php/entrelinhas/ article/viewFile/10378/4862. Acesso em: 30 jun. 2020.

BORRILLO, Daniel. Homofobia: história e crítica de um preconceito. 1. ed. 3. Reimp. - Belo Horizonte: Autêntica Editora, 2016.

BRASIL. Ministério da Educação (MEC). Base Nacional Comum Curricular - BNCC, versão aprovada pelo CNE, novembro de 2017. Disponível em: http://basenacionalcomum.mec.gov.br/wpcontent/uploads/2018/02/ bncc-20dez-site.pdf. Acesso em: 28 nov. 2020.

BRASIL. Ministério da Educação e do Desporto. Secretaria de Educação Fundamental. Parâmetros curriculares nacionais: orientação sexual. Brasília: MEC. 1997.

BUTLER, Judith. Problemas de gênero: Feminismo e subversão da identidade. Tradução de R. Aguiar. Rio de Janeiro: Civilização Brasileira, 2003 [1990]. 
CANDAU, Vera Maria Ferrão. Diferenças culturais, interculturalidade e educação em direitos humanos. Educação \& Sociedade, Campinas, v. 33, n. 118, p. 235-250, 2012. Disponível em: https://www.scielo.br/scielo.php?pid=S0101$73302012000100015 \&$ script=sci_arttext. Acesso em: 12 out. 2020.

CUNHA, Flávia Melo da. O túnel, o Frota, a ideologia de gênero. Ponto Urbe: Revista do núcleo de antropologia urbana da USP, São Paulo, v. 18, n. 1. 2016. Disponível em: https://journals.openedition.org/pontourbe/3137. Acesso em: 29 jan. 2021.

DIEGUEZ, Roberta Siqueira Mocaiber. A mulher transexual no discurso contemporâneo: um estudo de caso. DEMETRA: Alimentação, Nutrição \& Saúde, v. 11, n. 3, p. 521-538, Rio de Janeiro. 2016. Disponível em: https://www.e-publicacoes.uerj.br/index.php/demetra/article/view/22426. Acesso em: 24 jan. 2021.

ETTRICH, Débora da Gama. Construção das identidades de gênero e sexual no ambiente escolar: percepções, práticas pedagógicas e resolução de conflitos. 2019. Dissertação de Mestrado. Pontifícia Universidade Católica do Rio Grande do Sul.

FAIRCLOUGH, Norman. Analysing Discourse: textual analysis for social research. London: Routledge, 2003.

FAIRCLOUGH, Norman. Discurso e mudança social. Brasília: Universidade de Brasília, 2001.

FERNANDES, Clodoaldo Ferreira. Diversidade sexual na escola: o "normal" e o "anormal" em discursos de professores. 139f. Dissertação (Mestrado em Educação, Linguagem e Tecnologias). Universidade Estadual de Goiás, Anápolis, 2014.

FERNANDES, Clodoaldo Ferreira.; PEREIRA, Ariovaldo Lopes. "Príncipe ou cinderela?: fabricando identidades "(a)normais" no sujeito homoerótico In: Seminário Internacional Fazendo Gênero 10 (Anais Eletrônicos), Florianópolis, 2012. ISSN 2179-510X

FERNANDES, Clodoaldo Ferreira.; PEREIRA, Ariovaldo Lopes. O "normal" e o "anormal" em discursos de educadores: as dissidências sexuais na agenda escolar In: Ícone- Revista de Divulgação Científica em Língua Portuguesa, Linguística e Literatura Volume 18, n.2 - setembro de 2018 - ISSN 1982-7717.

FONTES, Malu. Ilustrações do silêncio e da negação: a ausência de imagens da diversidade sexual em livros didáticos. Revista psicologia política, v. 8, n. 16, p. 363-378, 2008.

FOUCAULT, Michel. História da sexualidade 1: a vontade de saber. 16. ed. Rio de Janeiro: Graal. 1999.

FOUCAULT, Michel. Vigiar e Punir: nascimento da prisão. Petrópolis, RJ: Vozes, 2014.

FOUCAULT, Michel. Ordem do discurso (A). Edições Loyola, 1996.

GANDRA, Alana. Escola é primeiro gargalo à inserção de pessoas trans no mercado. Agência Brasil. Publicado em 06 nov. 2019. Disponível em: https://agenciabrasil.ebc.com.br/geral/noticia/2019-11/escola-e-primeirogargalo-insercao-de-pessoas-trans-no-mercado. Acesso em: 11 jan. 2021.

GARCIA, Avany Aparecida; GABLER, Iracema. Identidade e diferença: a prática discursiva como estratégia nas aulas de língua materna. Educação e Emancipação, p. 99-118, 2013. Disponível em: http://www. periodicoseletronicos.ufma.br/index.php/reducacaoemancipacao/article/view/2631. Acesso em: $29 \mathrm{jan} .2021$.

GOMES, Nilma Lino. Movimento negro e educação: ressignificando e politizando a raça. Educação \& Sociedade, v. 33, n. 120, p. 727-744, 2012. Disponível em: https://www.scielo.br/pdf/es/v33n120/05. Acesso em: 22 nov. 2020 .

GUILOUSKI, Poliana Cristine Aureliano et al. Questões de gênero e diversidade na formação do adolescente: o ambiente escolar como espaço de ação. In: Congresso Estadual Paulista sobre Formação de Educadores. Universidade Estadual Paulista (UNESP), 2011. p. 5222-5228. Disponível em: https://repositorio.unesp.br/ handle/11449/139759. Acesso em: 09 dez. 2020.

HALL, S. A identidade cultural na pós-modernidade. Tradução de Tomaz Tadeu da Silva; Guacira Lopes Louro. 6. ed. Rio de Janeiro: DP\&A, 2001.

HALL, Stuart. Quem Precisa da Identidade? In: SILVA, Tomaz Tadeu da. Identidade e diferença: a perspectiva dos estudos culturais. Petrópolis/RJ: Vozes, 2014.

HERMANSON, Marcos. Relatório registra 420 vítimas fatais de discriminação contra LGBTs no Brasil em 2018. Brasil de Fato. São Paulo. Disponível em: https://www.brasildefato.com.br/2019/02/08/relatorio-registra-420vitimas-fatais-de-discriminacao-contra-lgbts-no-brasil-em-2018. Acesso em 22 jun. 2021. 
INTERDONATO, Giann Lucca; QUEIROZ, Marisse Costa de. Trans-identidade: a transexualidade e o ordenamento jurídico. Curitiba: Appris, 2017.

JESUS, Jaqueline Gomes. Trans-formações: poder e gênero nos novos tempos. Anais do $18^{\circ}$ Congresso Brasileiro de Psicodrama. Brasília: Federação Brasileira de Psicodrama. 2012.

JUNQUEIRA, Roberto Diniz. Diversidade Sexual na Educação: problematizações sobre a homofobia nas escolas/ Rogério Diniz Junqueira (organizador) - Brasília: Ministério da Educação, Secretaria de Educação Continuada, Alfabetização e Diversidade. 2009.

LEWIS, Elizabeth Sara. Do "léxico gay" à Linguística Queer. desestabilizando a norma homossexual oculta nas Teorias Queer. Estudos Linguísticos (São Paulo. 1978), v. 47, n. 3, p. 675-690, 2018. Disponível em: https:// revistas.gel.org.br/estudos-linguisticos/article/view/2049. Acesso em: 18 set. 2020.

LOPES, Denílson. Post-gay, teoria queer e cultura contemporânea. Palestra. Grupo de Estudos e Pesquisas "Violência, Racismo e Mídia: representações sociais e discursos midiáticos". Brasília, 2003.

LOURO, Guacira Lopes. Corpo, escola e identidade. Educação \& Realidade, v. 25, n. 2, 2000.

LOURO, Guacira Lopes. Gênero, sexualidade e educação: das afinidades políticas às tensões teóricometodológicas. Educação em Revista, n. 46, p. 201-218, 2017. Disponível em: https://www.scielo.br/scielo. php?pid=S0102-46982007000200008\&script=sci_abstract\&tlng=pt. Acesso em: 12 nov. 2020.

LOURO, Guacira Lopes. Gênero, sexualidade e educação: uma perspectiva pós-estruturalista. 11. ed. Rio de Janeiro: Vozes, 2010.

LOURO, Guacira Lopes. Um corpo estranho: ensaios sobre sexualidade e teoria queer. Autêntica, 2018a.

LOURO, Guacira Lopes. O corpo educado: pedagogias da sexualidade. Autêntica, 2018b.

MOITA LOPES, Luiz Paulo da. Identidades fragmentadas. A construção discursiva de raça, gênero e sexualidade em sala de aula. Campinas: Mercado de Letras, 2006.

MOITA LOPES, Luiz Paulo da. Sexualidades em sala de aula: discurso, desejo e teoria queer. In: MOREIRA, A.F. CANDAU, V.M. (Orgs.) Multiculturalismo: Diferenças culturais e práticas pedagógicas. 3. ed. Rio de Janeiro: Vozes, 2008.p.125-148.

MENDES, Patrícia de Oliveira e Silva Pereira. et al. A retirada dos termos "igualdade de gênero e orientação sexual" do Plano Nacional de Educação-PNE 2014-2024. Diversidade e Educação, v. 8, n. 2, p. 128-151, 2020. Disponível em: https://seer.furg.br/divedu/article/view/12282. Acesso em: 19 de mar. 2021.

NETTO, José Pedro Simões. A produção acadêmica sobre diversidade sexual. Revista Em Pauta: teoria social e realidade contemporânea, n. 28, p. 65-82, 2011. Disponível em: https://xdocs.com.br/doc/simoes-machado-ezuco-08p2rdr69rnv. Acesso em: 27 jan. 2021.

NISHIMOTO, Camila. Dia do Orgulho Agênero: guia básico para entender essa identidade. @TODXBrasil. 19 maio 2020. Disponível em: https://medium.com/todxs/dia-do-orgulho-agenero-guia-básico-para-entender-essaidentidade-e2edea5e9ab2. Acesso em: 23 fev. 2021.

OFFERNI, Rodrigo Leonardo. Escola sem partido: origem e modus operandi de um movimento liberal-conservador e desdobramentos para os conteúdos de sociologia e história. 2020.

OLIVEIRA, Danilo Araújo; FERRARI, Anderson. VIGILÂNCIA DA SEXUALIDADE E HETERONORMATIVIDADE NO CURRICULO ESCOLAR. Linguagens, Educação e Sociedade, n. 46, p. 3862, 2020. Disponível em: https://revistas.ufpi.br/index.php/lingedusoc/article/view/10373. Acesso em: 23 jun. 2021.

OLIVEIRA, Danilo Araújo. Discursos heteronormativos e produção de sujeitos generificados no currículo escolar. Margens Interdisciplinar, v. 11, n. 17, p. 92 - 107, 2020. Disponível em: https://periodicos.ufpa.br/index.php/ revistamargens/article/view/5436. Acesso em: 04 nov. 2020.

POCAHY, Fernando Altair. Identidade, sexualidade e gênero na escola - Conexão Futura - Canal Futura. 11 fev. 2015. Disponível em: https://www.youtube.com/watch?v=untgDR-goN8. Acesso em: 22 abr. 2021.

RICH, Adrienne. Compulsory heterosexuality and lesbian existence. Signs: Journal of women in culture and society, v. 5 , n. 4, p. 631-660, 1980.

SANTOS, Fabiana Castor; LUCINI, Marizete. Representações sociais, identidade de gênero e diversidade sexual 
na formação docente. Revista Faz Ciência, 2016. Disponível em: https://ri.ufs.br/bitstream/riufs/8865/2/ IdentidadeGeneroFormacaoDocente.pdf. Acesso em: 03 fev. 2021.

SANTOS FILHO, Ismar Inácio. Sexo, sexualidade e gênero na formação de professores. Observatório da Imprensa,840. São Paulo. p. 01 - 03, 03 mar. 2015. Disponível em: Sexo, sexualidade e gênero na formação de professores | Observatório da Imprensa (observatoriodaimprensa.com.br) Acesso em: 20 jun. 2021.

SILVA, Linda Carter Souza da.; SILVA FILHO, Luiz Gomes da. Inclusão e Direitos humanos: dialogando sobre políticas públicas para pessoas com deficiência. In: II Seminário Potiguar: Educação, Diversidade e Acessibilidade. 2015. Disponível em: http://www.uern.br/controledepaginas/edicao-atual-/arquivos/367818_ semina i riopotiguar_uern_(1)_nafo_apresentou.pdf. Acesso em: $02 \mathrm{dez} .2020$.

SILVA, Tomaz Tadeu da. A produção social da identidade e diferença. In: SILVA, Tomaz Tadeu (org.). Identidade e diferença: a perspectiva dos estudos culturais. Petrópolis: Vozes, p. 60-102, 2000.

SKLIAR, Carlos Bernardo. A educação e a pergunta pelos Outros: diferença, alteridade, diversidade e os outros "outros". Ponto de Vista: Revista de educação e processos inclusivos, Florianópolis, no . 05, p. 37-49, 2003. Disponível em: https://periodicos.ufsc.br/index.php/pontodevista/article/view/1244. Acesso em: 04 de fev. 2021.

SOARES, Wellington. Precisamos falar sobre Romeo... ... Iana, Roberta e Emilson. A escola trata com preconceito quem desafia as normas de papéis masculinos e femininos. Revista Nova Escola, 279, (ISSN 0103-0116) ano 30, fev. 2015, São Paulo: Editora Abril, 2015. Disponível em: https://novaescola.org.br/conteudo/80/educacao-sexualprecisamos-falar-sobre-romeo. Acesso em: 26 jan. 2021.

SODRÉ, Muniz. Reinventando a educação: diversidade, descolonização e redes. Editora Vozes Limitada, 2012.

VALE DE ALMEIDA, Miguel. Gênero, masculinidade e poder: revendo um caso do Sul de Portugal. Anuário Antropológico/95, p. 161-189, 1996. Disponível em: https://edisciplinas.usp.br/pluginfile.php/269228/mod_ resource/content/0/genero-masculinidade-e-poder.pdf. Acesso em: 14 nov. 2020.

XAVIER FILHA, Constantina. Identidade, sexualidade e gênero na escola - Conexão Futura - Canal Futura. 11 fev. 2015. Disponível em: https://www.youtube.com/watch?v=untgDR-goN8. Acesso em 22 abr. 2021. 